\title{
Evaluation of Subclavian, Thoracic Aorta, and Innominate Ar- tery Injuries in Blunt Trauma Mechanisms: A Systematic Re- view of Case Reports and Case Series
}

\author{
Nebiyou Seyoum ${ }^{a}$, Segni Kejela ${ }^{a^{*}}$ \\ ${ }^{a}$ Department of surgery, Tikur Anbessa Specialized Hospital, Addis Ababa University, College of Health Sciences, Ethiopia.
}

\begin{abstract}
Background: Blunt thoracic arterial injuries are among the rare causes for presentation at trauma centers. Most of the literature on these injuries is in the form of case reports and case series, with no significantly consolidated data available.

Methods: A systematic review of English language case reports and case series from 2000 to 2019 was carried out using the PubMed and Google Scholar search engines.

Results: The mean patient ages were $35.9,36.4$, and 44.3 years for thoracic aorta, innominate, and subclavian artery injuries, respectively. Of the innominate artery injury patients, $89.7 \%$ were male. Motor vehicle-related injuries contributed to $50.9 \%$ of thoracic aortic injuries. A blood pressure/pulse deficit was recorded in $34.8 \%$ and $20.7 \%$ of patients with subclavian and innominate artery injuries, respectively, and chest pain and hemodynamic instability were found in $23.5 \%$ and $20.5 \%$ of aortic injury patients, respectively. Clavicular fracture was the most common associated finding in subclavian artery injury patients at $42 \%$. Computed tomography was performed in $21.7 \%, 47.1 \%$, and $27.6 \%$ of patients with subclavian artery, thoracic aorta, and innominate artery injuries, respectively. An endovascular intervention was performed in $44.1 \%$ of patients with subclavian artery injuries.

Conclusion: Injury to the subclavian artery is relatively common among the older population. Blood pressure or pulse discrepancies could point to either subclavian or innominate artery injury. An endovascular intervention can be considered in all patients but must be individualized based on patient and facility factors.

Keywords: Aortic rupture; clavicular fracture; traumatic pseudoaneurysm; endovascular repair; cerebrovascular accident
\end{abstract}

\section{INTRODUCTION}

Trauma is the most common cause of mortality in children and adults under 44 years of age ${ }^{[1]}$. Blunt trauma is the leading mechanism affecting patients in most civilian trauma centers ${ }^{[2,3]}$. Furthermore, motor vehicle accidents are the principal cause of blunt trauma, accounting for 1.3 million deaths, $20 \mathrm{~s}-50$ million non-fatal injuries, and $29 \%$ of all trauma cases annually ${ }^{[4,5]}$. The overall incidence of vascular trauma is $5 \%$, with a larger fraction contributed by penetrating trauma mechanisms ${ }^{[6,7]}$. In fact, trauma centers report that only $5 \%$ of vascular trauma cases are caused by

* Corresponding author: Segni Kejela

Mailing address: Department of surgery, Tikur Anbessa Specialized Hospital, Addis Ababa University, College of Health Sciences, Ethiopia.

E-mail: segnikejo@gmail.com blunt mechanisms ${ }^{[8]}$. However, this may be an underestimation because many blunt trauma patients with major vascular injuries do not survive long enough to reach a healthcare facility. The findings of postmortem examinations of prehospital trauma deaths support this notion, placing blunt major vascular trauma as the second most common cause of death, after head injury $[9,10]$.

The paucity of blunt vascular injuries in trauma centers is reflected in the literature; most of the relevant publications are case reports and case series ${ }^{[11]}$.

This review is intended to integrate the experiences of centers around the world through the analysis of case reports and case series concerning this issue and hopefully fill the knowledge gaps surrounding the epidemiological changes, investigative modality advancements, and management innovations for blunt vascular trauma.

\section{METHODS}

Received: 31 October 2019 Accepted: 05 December 2019 


\section{Data source and search strategy}

PubMed and Google Scholar were utilized to search for publications between January 2000 and September 2019 posing no language restrictions to the authors. The following key statements were utilized to initiate the search process: "case report/case series, subclavian artery injury," "case report/case series, thoracic aorta injury," and "case report/case series, innominate artery injury."

\section{Inclusion criteria}

All case reports and case series on subclavian, thoracic aorta, and innominate artery injuries arising from blunt mechanisms with no missing publication segments and published in English were included.

Only publications from January 2000 to September 2019 were included.

\section{Exclusion criteria}

The exclusion criteria were as follows: any blunt vascular injuries not involving the subclavian artery, thoracic aorta, or innominate artery.

All reports of vascular injury with a penetrating mechanism of trauma were excluded.

Publications that are primarily produced in a language other than English were excluded.

\section{Data extraction and handling}

From each patient report, the following information was retrieved: year of reported case, age at presentation, sex, mechanism of injury, general complaint/clinical presentations, associated injuries, specific vertebral injury, intracranial injury, associated vascular injuries (in addition to the injured vessels under study), chest wall injuries, pulmonary injuries, facial injuries, limb injuries, abdominal injuries, specific type of vascular injury for the main thoracic arterial injuries under question, diagnostic modality utilized, treatment provided, type of open surgical treatment provided, and outcome with specific complications pertaining to the vascular injury and mortality. No effort was made to communicate with authors concerning missing data from the publications.

\section{Data synthesis and analysis}

The generated data was entered into SPSS version 23 in the categories mentioned above, and the accuracy of the data was evaluated and ascertained.

After the data entry and cleanup were complete, the data analysis was conducted using the same software: SPSS version 23.

\section{RESULTS}

\section{Subclavian artery injury}

The cases of a total of 46 patients with subclavian artery injuries were reviewed (Table 1). The mean age of the patients was $44.33 \pm 21.11$ years, and $73.8 \%$ were male. Motor vehicle collisions were involved in $32.6 \%$ of the cases. Motor vehicle-related injuries were reported in $13(65 \%)$ patients younger than 45 years of age. Patients older than 45 years of age presented due to a falling accident in $36.4 \%$ of the reported cases. Of the female patients with subclavian artery injuries, half presented due to a falling accident.

Hemodynamic instability was recorded in $21.7 \%$ of the patients as a main clinical presenting sign/symptom, and polytrauma was reported in 10 (21.7\%) of the patients. The most common clinical manifestations of motor vehicle-related subclavian artery injuries were blood pressure/pulse deficit ( 9 patients, 45\%) and hemodynamic instability (7 patients, $35 \%$ ). Patients presenting with subclavian artery injury after falling accidents reported progressive supraclavicular swelling in $5(63.5 \%)$ cases. Three out of the 5 patients presenting with sports-related injuries presented with a blood pressure/pulse deficit.

Concerning associated injuries, clavicular fracture was reported in 24 (52.2\%) cases. Of the patients with subclavian artery injuries and clavicular fractures, 62.5\% were 45 years of age or older. Four (8.7\%) of the patients had reported traumatic brachial plexopathy, and $10(21.7 \%)$ of the patients presented with polytrauma. Of the reviewed patients, 15 (32.6\%) had a pneumothorax, hemothorax, or both at presentation (Table 2). Regarding the diagnostic modalities utilized, 44 cases reported the use of 1 or more imaging techniques. Conventional/digital subtracted angiography was utilized in 13 (28.3\%) of the reported cases, and doppler ultrasonography, contrast CT, and CT angiography were used in 3 (6.5\%), 10 (21.7\%), and 12 (26.1\%) cases, respectively. One patient had a chest x-ray as the sole imaging modality for diagnosis. A combination of CT angiography and conventional angiography with Doppler ultrasonography was conducted in 2 (4.3\%) patients.

The types of vascular injuries diagnosed using imaging modalities or with intra-operative findings were reported in all 46 patients in this review. Pseudoaneurysm and dissection were reported in 20 (43.5\%) and $8(17.4 \%)$ of the cases, respectively. Rupture, laceration, and compression occurred in 4 (15.2\%), 6 (13\%), and $3(6.5 \%)$ of the cases, respectively. One patient presented with a spasm of the subclavian artery.

The treatment modalities were specified in all 46 of the reviewed cases, with open surgical repair performed in 21 (45.7\%) cases and endovascular and hybrid procedures performed in 17 (37\%) and 5 (10.9\%) cases, respectively. Three patients underwent conservative/ medical therapy. Within the open surgical repair group, $11(57 \%)$ underwent graft repair. Of the graft repair patients, $3(27.3 \%), 2$ (18.1\%), and 2 (18.1\%) underwent a prosthetic interposition graft, a prosthetic carotid-subclavian bypass, and a prosthetic carotid-axillary bypass graft, respectively. In addition, 3 (27.3\%) 


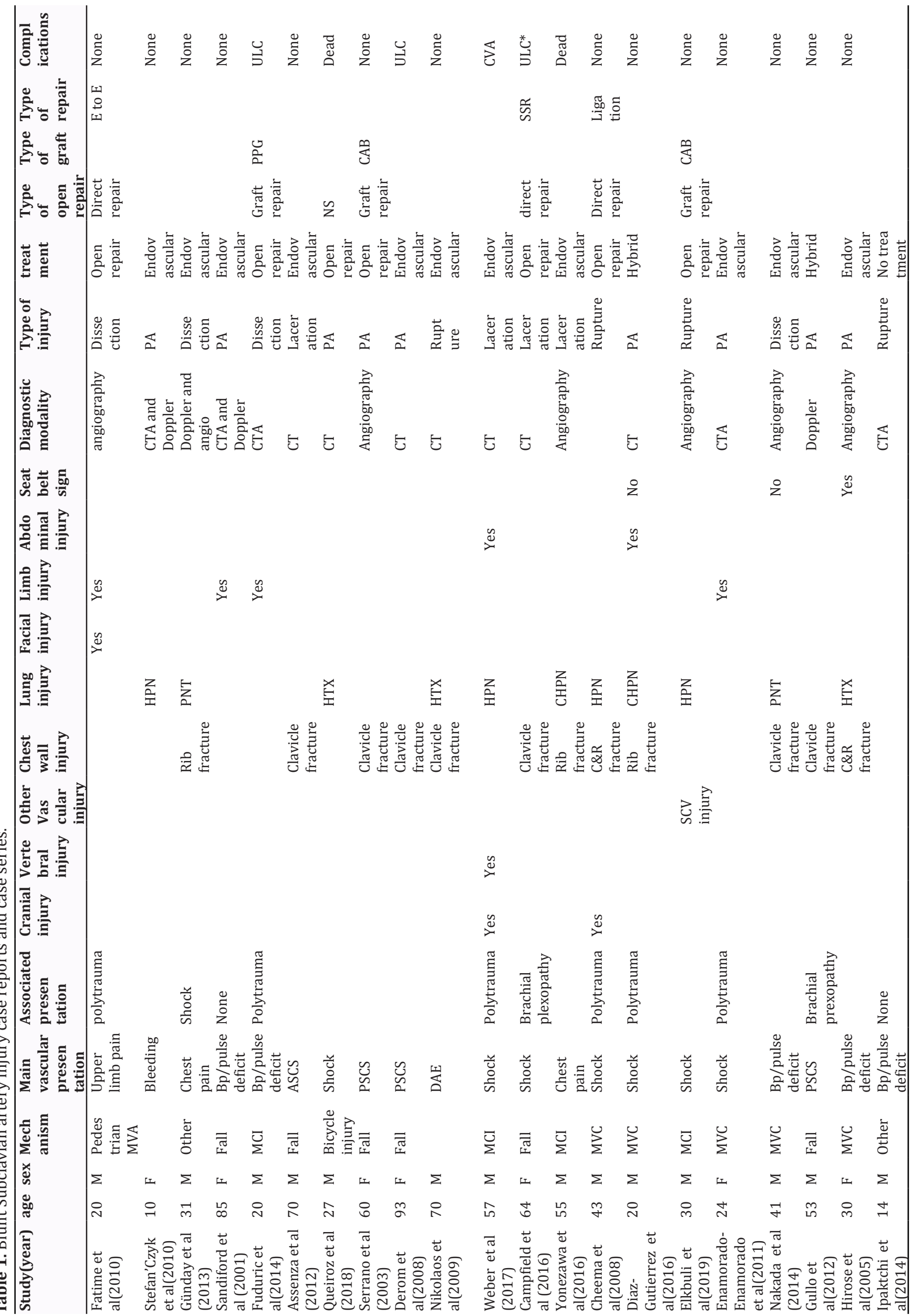




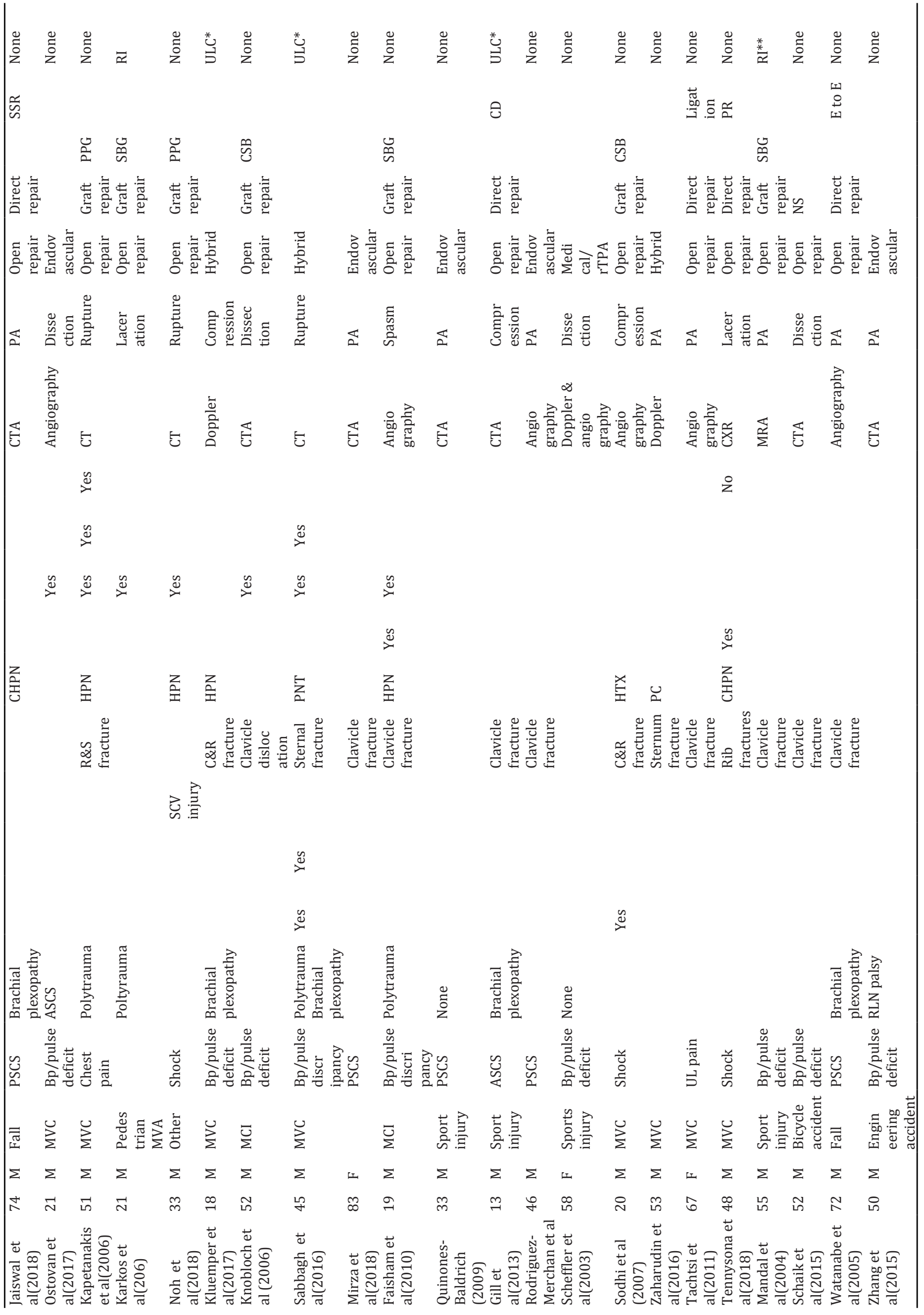




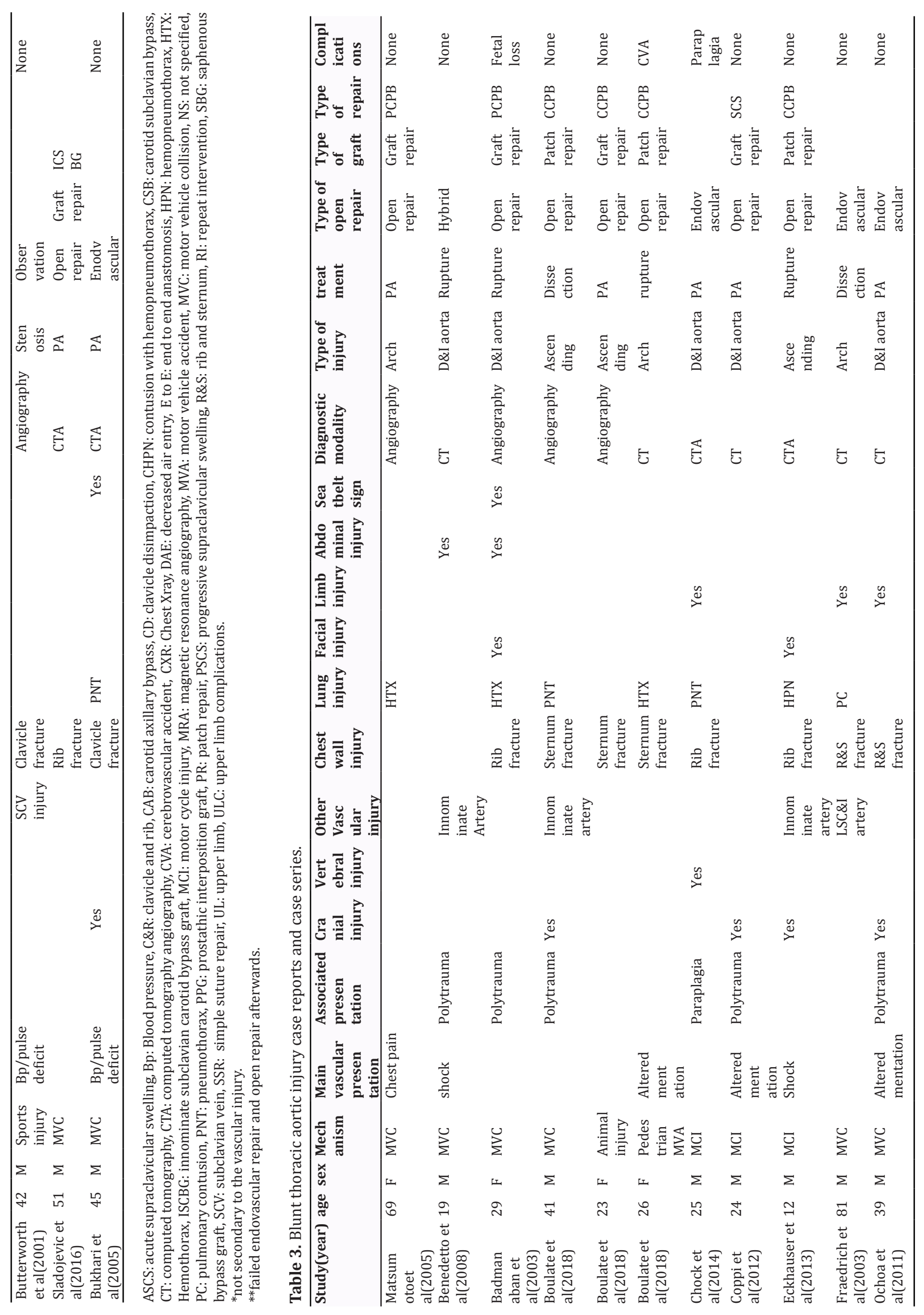




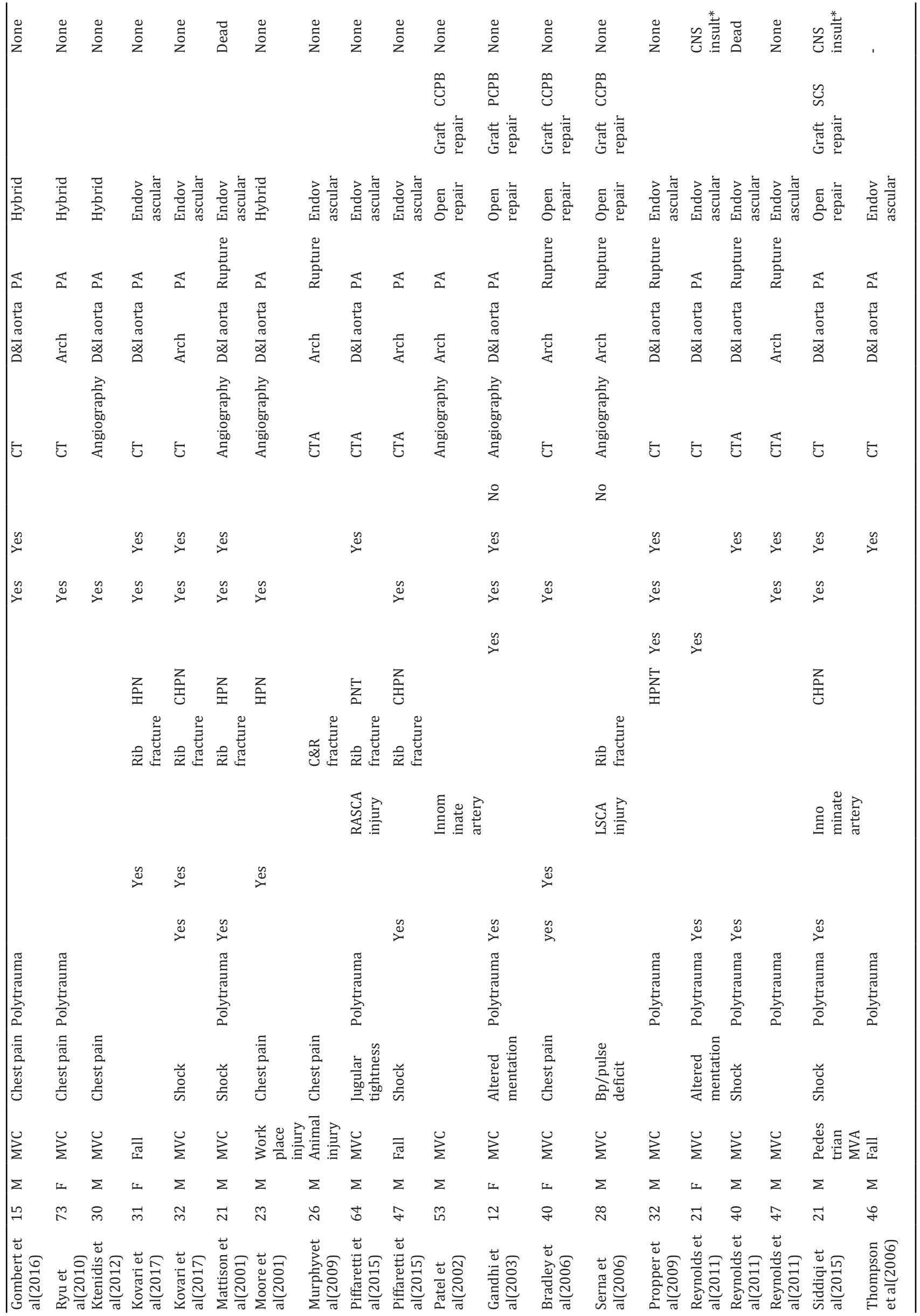




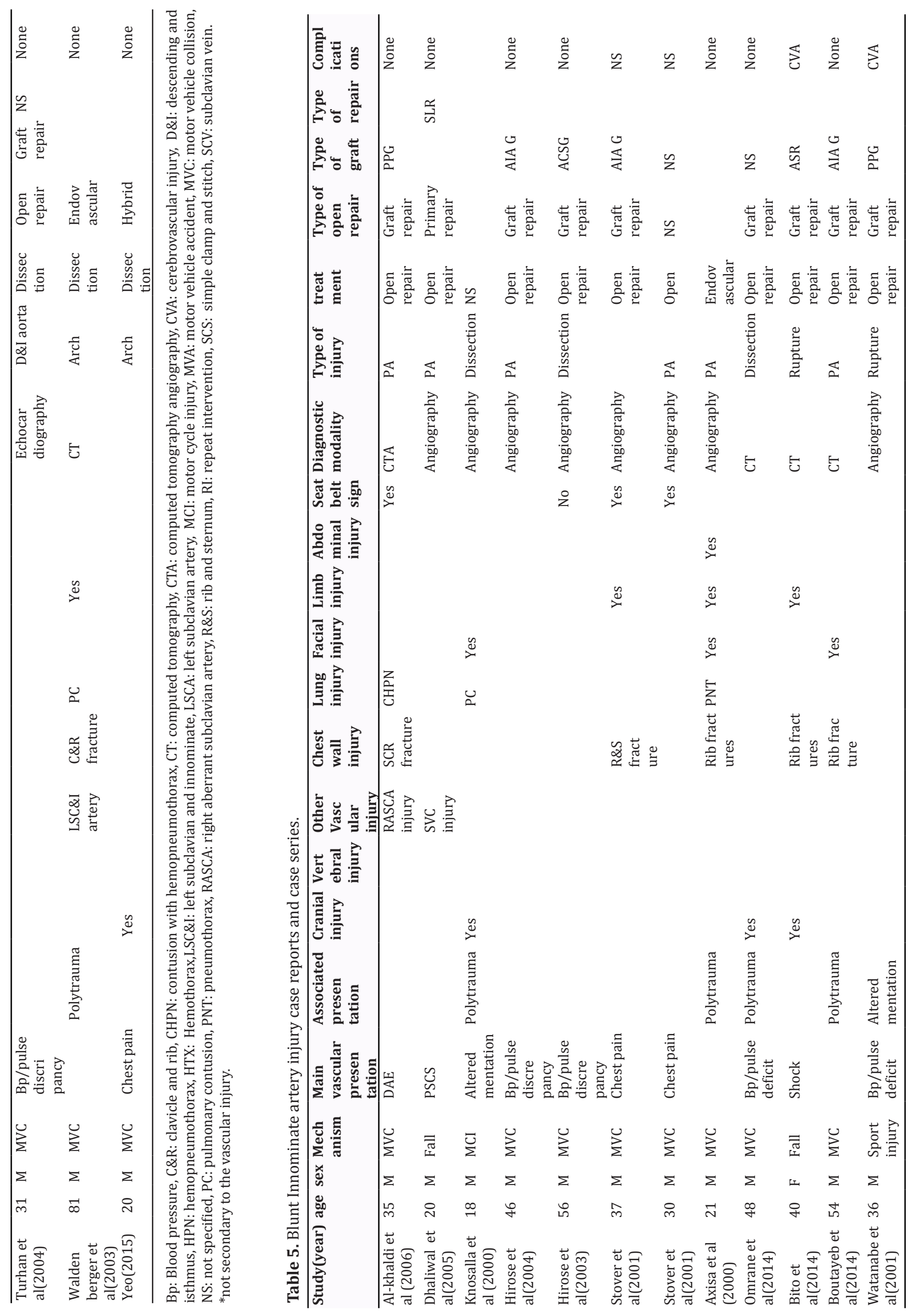




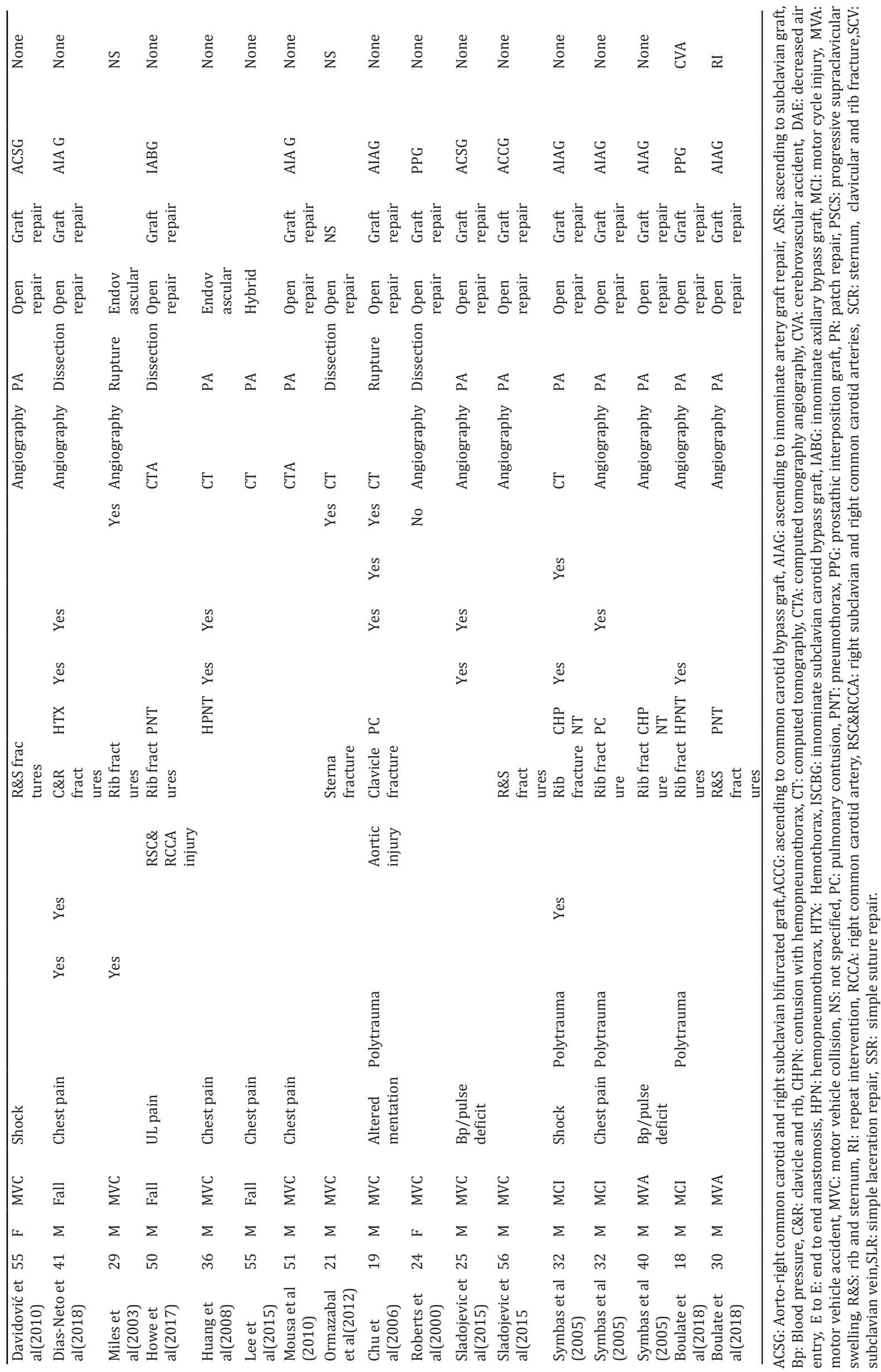


patients underwent a saphenous bypass graft, 8 (42.1\% of the open repair cases) patients had direct repairs with end-to-end anastomosis, a simple suture and ligation were performed in 2 (25\%) patients, and 1 patient underwent a patch repair.

The outcomes and complications were reported in 45 of the 46 cases, with $73.9 \%$ of patients experiencing total resolution and 6 (13\%) experiencing upper limb complications, of which 4 were confirmed brachial plexopathy at presentation rather than vascular injury-related complications. Repeat intervention was needed in $2(4.3 \%)$ patients, and $2(4.3 \%)$ patients died. Furthermore, 1 patient was diagnosed with a cerebrovascular accident related to the subclavian artery injury.

\section{Thoracic Aorta injury}

The data for a total of 34 aortic injury patients was retrieved from the literature between 2000 and 2019 (Table 3). The mean age of the patients with aortic injuries was $35.9 \pm 18.9$ years, and $26(76.5 \%)$ of the patients were male. Of the patients examined, 23 (67.6\%) presented after a motor vehicle collision, and 28 $(82.4 \%)$ had injuries related to motor vehicles (including pedestrian motor vehicle accidents and motorcycle injuries). Hemodynamic instability (hypotension) and chest pain were the chief clinical features in 7 (20.6\%) and $8(23.5 \%)$ of the cases, respectively. Polytrauma was reported in 17 (50\%) of the patients. Twenty-one $(84 \%)$ of the patients aged under 45 years had motor vehicle-related injuries, compared to 7 (77.7\%) of the patients aged 45 years or older. Female patients presented after motor vehicle accidents in $87.5 \%$ of the cases, compared to $80.7 \%$ in male patients.

Rib fracture was the most common associated chest wall injury, presenting in $9(26.9 \%)$ of the cases overall and in $3(8.8 \%)$ and 1 (2.9\%) cases with sternum and clavicle fractures, respectively. Hemopneumothorax alone was reported in $5(14.7 \%)$ patients, and with lung contusion in $3(8.8 \%)$ patients. Five (14.7\%) patients had an abdominal-associated innominate artery injury, and 13 (38.2\%) patients had an associated traumatic brain injury (Table 4).

The most common imaging modalities utilized were contrast CT scanning and CT angiography, which were used in 16 (47.1\%) and 7 (20.6\%) cases, respectively, and conventional/digital subtracted angiography was used in 10 (29.4\%) cases. The most common sites of injury were the isthmus and the descending aorta, accounting for 18 (52.9\%) of the examined cases. The aortic arch and the ascending aorta were injured in 13 (38.2\%) and 3 (8.8\%) cases, respectively. A pseudoaneurysm was discovered in 18 (52.9\%) of the patients using an imaging modality or intraoperative findings. Rupture was diagnosed in 11 (32.4\%) cases and dissection with or without thrombosis in 5 (14.7\%) cases. Regarding treatment, 13 (38.2\%) patients underwent open surgical repair, with endovascular repair performed in 15 (44.1\%) and a hybrid method in 6 $(17.6 \%)$ cases. In the open repair group 10 out of 13 (76.9\%) of the patients underwent a repair using a prosthetic graft, and $3(23.1 \%)$ underwent a patch repair. The majority of the open procedures -7 cases (53.8\%)-were performed under a complete cardiopulmonary bypass with deep hypothermic arrest and a centrifugal pump (3 cases, $23.1 \%$ ). Two patients underwent a simple clamp and stitch procedure with no bypass.

In terms of the outcomes and complications in the aortic injury patients, $76.5 \%$ experienced complete resolution, with 2 deaths out of the 34 patients reported. Three (9\%) patients had chronic cerebral sequele, with 2 of the 3 cases caused by traumatic brain injury.

\section{Innominate artery injury}

The data of a total of 29 patients was retrieved from reports from 2000 to 2019 (Table 5). The mean age of the patients with innominate artery injuries was $36.4 \pm 12.8$ years, and $26(89.7 \%)$ of the patients were male. Motor vehicle collisions contributed to 19 $(65.5 \%)$ of the innominate artery injury cases, with motor vehicle associated-injuries accounting for $79.3 \%$ of the cases. Regarding the clinical presentations of the innominate artery injury patients, chest pain and blood pressure/pulse deficit were reported in 7 (24.1\%) and $6(20.7 \%)$ cases, respectively. Polytrauma was reported in $8(27.6 \%)$ cases.

Rib fracture alone was reported in 9 (31\%) patients and with sternum fracture in $4(13.8 \%)$ patients. Lung contusion alone was reported in $3(10.3 \%)$ patients and with hemopneumothorax in another 3 (10.3\%). Eight $(27.6 \%)$ of the cases included facial injuries. Extremity injuries were reported in 8 of the 29 patients $(27.6 \%)$, and $6(20.7 \%)$ had a seatbelt sign (Table 6). Regarding diagnostic imaging and treatment modalities, angiography (conventional/digital subtracted) was utilized in $18(62.1 \%)$ cases. A contrast CT scan and CT angiography were performed in 8 (27.6\%) and $3(10.3 \%)$ cases, respectively. A pseudoaneurysm was identified using imaging modalities or intraoperative findings in $58.6 \%$ of the reported cases, whereas $24.1 \%$ of the cases had dissection with or without intravascular thrombosis, and rupture was present in $13.8 \%$ of the cases.In 1 case, the type of innominate injury was not further specified. Twenty-four (82.8\%) patients underwent open surgical repair: 3 patients were treated with an endovascular technique, and 1 patient was treated with a hybrid method. Twenty-one of the $24(87.5 \%)$ patients treated with open repair underwent a graft repair, and 1 patient was treated with a direct suture repair. Two cases did not specify the method of open repair used. Among the patients in the graft repair group, 10 (47.6\%) had an ascending aorta to innominate artery bypass graft, whereas 3 (14.3\%) had an aorto-right common carotid and right subclavian bifurcated bypass graft. An interposition graft was 
performed in 4 (19\%) patients, and ascending aorta to common carotid artery bypass, innominate to axillary artery bypass graft, and ascending aorta to subclavian artery bypass procedures were performed in 1 patient each.

Among the patients with innominate artery injuries, $69 \%$ experienced complete resolution and were symptom free at follow-up, $10.3 \%$ of the patients had a cerebrovascular accident pertaining to the arterial injuries, and 1 patient required a repeat intervention.

\section{DISCUSSION}

\section{Subclavian artery injury}

Subclavian artery injuries were more common in males, corresponding with the results of a report by Sturm et al. in 1984, which included 80\% (12 out of 15 patients) male patients ${ }^{[108]}$. The mean age of the patients examined in this review was relatively older than that of the report of 26.2 years by Sturmet al.but relatively younger than a case series published in 2001 from cases treated before 1998, which reported a mean age of 57 years ${ }^{[107,108]}$.

Motor vehicle-related injuries were reported in almost half of the reviewed cases as a mechanism of trauma, which is low compared to other studies ${ }^{[107-109]}$. Motor vehicle-related injuries were found to be more common among males than females in this review, corresponding to a significantly higher rate of motor vehicle-related fatalities among males than among females ${ }^{[110]}$. A point worth mentioning is the high proportion of fall-related subclavian artery injuries in older patients, which has never been previously reported in systematic reviews.

The most common clinical presenting signs and symptoms in the reviewed cases were blood pressure/pulse deficit and hemodynamic instability. This is certainly not an outlier in the context of blunt subclavian artery injuries. Katras et al.reported that 7 out of the 15 patient cases they reviewed included hypotension (unstable hemodynamic status), and 7 out of 15 included diminished or absent pulse ${ }^{[107]}$. Patients with subclavian artery injuries after a fall had a less dramatic, but more progressive presentation of progressive supraclavicular swelling, pointing toward the necessity for a more vigilant follow-up in these cases.

Clavicular fracture was the most common associated fracture in patients with subclavian artery injuries, with more than half of patients presenting with this fracture. This finding has been replicated by multiple reviews articles published by other authors ${ }^{[107-109]}$. Concerning imaging modalities, conventional/digital subtracted angiography was the most commonly utilized technique, followed by CT angiography and standard contrast CT scanning. In the present review, conventional angiography was used less frequently than in previous reviews. This is consistent with a review by Sturm et al., in which 14 of the 15 patients underwent conventional diagnostic angiography before operative management was performed. In addition, Costa and Robbs reported that conventional angiography was performed in all 11 patients for whom operative management was provided ${ }^{[108,109]}$. Investigative modalities have found that most vascular lesions are pseudoaneurysms. However, this was not exhibited in a review by Katras et al,in which only 2 of the 7 patients had pseudoaneurysm of the subclavian artery ${ }^{[108]}$.

Endovascular and hybrid methods of treatment together have contributed to managing $48 \%$ of subclavian artery injuries, which certainly demonstrates a significant shift from the previous reports from the end of the past century. In all 3 of the reports examined from this period-those of Strum et al., Katras et al.,and Costa and Robbs-only open repair was reported in all of the patients ${ }^{[107-109]}$. In the present review, the open repair group underwent more graft repairs than primary/direct sutures, which is similar to Costa and Robbs' report $^{[109]}$.

Regarding patient outcomes, 6 out of the 46 patients in this review experienced upper limb complications due to either vascular or non-vascular causes. This outcome was significantly rarer than in the 7 out of 15 patient cases with limb complications in Costa and Robbs' report ${ }^{[109]}$. This may be due to recent improvements in operative techniques and the advent of endovascular and hybrid techniques.

\section{Thoracic aorta injury}

More than 3/4ths of the patients with blunt thoracic aortic injury in this review were male, with motor vehicle-related injuries being the most common mechanism. This corresponds to a larger study from Germany, in which $77.5 \%$ of the patients with blunt thoracic aorta injuries were male, and high-speed motor vehicle accidents caused $78 \%$ of the blunt thoracic aortic injuries $^{[111]}$.

The most common clinical manifestations in this review were chest pain and hemodynamic instability (hypotension). Hemodynamic instability was more common in a German study, appearing in $35.6 \%$ to $70.1 \%$ of cases depending on the vascular lesions in question ${ }^{[111]}$. Polytrauma was reported in the present review in half of patients, and cervical and thoracic vertebral injuries were reported in significant number of patients at, $14.7 \%$, although no prior data is available for comparison.

Rib fracture is the most common chest wall trauma associated with blunt thoracic aorta injury. There is also a high rate of associated traumatic brain injury among blunt thoracic aorta injuries. An autopsy report by Burkhart et al.showed higher rates of rib fracture and traumatic brain injury (69\% and 68\%, respectively) than this review $\left(26.9 \%\right.$ and $38.2 \%$, respectively) ${ }^{[12]}$. This may be because autopsy cases have an expected higher severity of injury than the patient cases examined in the present review. In addition, in the present review, 
Table 2. Demographics, mechanism of injury and clinical manifestations of patients with Subclavian artery injuries.

\begin{tabular}{|c|c|c|c|}
\hline Category & Subcategory & Number & Percentage(\%) \\
\hline \multirow[t]{3}{*}{ Age category } & $1-17$ years & 3 & 6.5 \\
\hline & $18-44$ years & 18 & 45.7 \\
\hline & 45 years and above & 25 & 54.3 \\
\hline \multirow[t]{2}{*}{ Sex } & Male & 36 & 78.3 \\
\hline & Female & 10 & 21.7 \\
\hline \multirow[t]{8}{*}{ Mechanism of injury } & Pedestrian motor vehicle accident & 2 & 4.3 \\
\hline & Motor vehicle collision & 15 & 32.6 \\
\hline & Motor cycle injury & 6 & 13.0 \\
\hline & Falling down accident & 8 & 17.4 \\
\hline & Sports injury & 5 & 10.9 \\
\hline & Bicycle & 3 & 6.5 \\
\hline & Workplace injury & 2 & 4.3 \\
\hline & Other and non specified & 5 & 10.9 \\
\hline \multirow[t]{9}{*}{ Clinical presentation } & Blood pressure or pulse deficit & 16 & 34.8 \\
\hline & Hemodynamic instability & 10 & 21.7 \\
\hline & $\begin{array}{l}\text { Progressive supraclavicular } \\
\text { swelling }\end{array}$ & 8 & 17.4 \\
\hline & Decreased Air entry & 1 & 2.2 \\
\hline & Upper limb pain & 2 & 4.3 \\
\hline & Acute supraclavicular swelling & 2 & 4.3 \\
\hline & Chest pain/dyspnea & 3 & 6.5 \\
\hline & External bleeding & 1 & 2.2 \\
\hline & Non-specified & 3 & 6.5 \\
\hline \multicolumn{4}{|l|}{ Associated injuries } \\
\hline \multirow[t]{7}{*}{ Chest wall injuries } & Chest wall injury & & \\
\hline & Clavicle fracture alone & 19 & 41.3 \\
\hline & Rib fracture alone & 5 & 10.9 \\
\hline & Sternum fracture alone & 2 & 4.3 \\
\hline & Rib and clavicle fracture & 5 & 10.9 \\
\hline & Rib and sternum fracture & 1 & 2.2 \\
\hline & None/not reported & 14 & 30.4 \\
\hline \multirow[t]{7}{*}{ Lung/intrathoracic injury } & $\begin{array}{l}\text { Lung parenchymal/intrathoracic } \\
\text { injury }\end{array}$ & & \\
\hline & Pneumothorax alone & 4 & 8.7 \\
\hline & Hemothorax alone & 4 & 8.7 \\
\hline & Hemopneumothorax & 7 & 15.2 \\
\hline & Lung contusion alone & 1 & 2.2 \\
\hline & $\begin{array}{l}\text { Lung contusion with } \\
\text { hemopneumothorax }\end{array}$ & 3 & 6.5 \\
\hline & None/Not reported & 27 & 58.7 \\
\hline \multirow[t]{5}{*}{ Other area injuries } & Face injury & 3 & 6.5 \\
\hline & Subclavian vein injury & 1 & 2.2 \\
\hline & Extremity injury & 11 & 23.9 \\
\hline & Abdominal injury & 4 & 8.7 \\
\hline & Traumatic brain injury & 5 & 10.9 \\
\hline
\end{tabular}


ANT PUBLISHING CORPORATION

Published online: 27 December 2019

Table 4. Demographics, mechanism of injury and clinical manifestations of patients with Subclavian artery injuries.

\begin{tabular}{|c|c|c|c|}
\hline Category & Subcategory & Number & Percentage(\%) \\
\hline \multirow[t]{3}{*}{ Age category } & $1-17$ years & 3 & 8.8 \\
\hline & 18-44 years & 22 & 64.7 \\
\hline & 45 years and above & 9 & 26.5 \\
\hline \multirow[t]{2}{*}{ Sex } & Male & 26 & 76.5 \\
\hline & Female & 8 & 23.5 \\
\hline \multirow[t]{6}{*}{ Mechanism of injury } & Pedestrian motor vehicle accident & 2 & 5.9 \\
\hline & Motor vehicle collision & 23 & 67.6 \\
\hline & Motor cycle injury & 3 & 8.8 \\
\hline & Fall from height & 3 & 8.8 \\
\hline & Animal related injury & 2 & 5.9 \\
\hline & Workplace injury & 1 & 2.9 \\
\hline \multirow[t]{6}{*}{ Clinical presentation } & Chest pain & 8 & 23.5 \\
\hline & Hemodynamic instability & 7 & 20.6 \\
\hline & Altered mentation & 5 & 14.7 \\
\hline & Blood pressure or pulse deficit & 2 & 5.9 \\
\hline & Other & 3 & 8.8 \\
\hline & Non-specified & 9 & 25.6 \\
\hline Related complaint & Polytrauma & 17 & 50 \\
\hline \multirow[t]{5}{*}{ Chest wall injury } & Rib fracture alone & 9 & 26.9 \\
\hline & Sternum fracture alone & 3 & 8.8 \\
\hline & Sternum and rib fracture & 3 & 8.8 \\
\hline & Rib and clavicle fracture & 1 & 2.9 \\
\hline & None/not reported & 18 & 52.9 \\
\hline \multirow{6}{*}{$\begin{array}{l}\text { Lung parenchymal/ intrathoracic } \\
\text { injury }\end{array}$} & Pneumothorax alone & 3 & 8.8 \\
\hline & Hemothorax alone & 3 & 8.8 \\
\hline & Hemopneumothorax & 5 & 14.7 \\
\hline & Lung contusion alone & 2 & 5.9 \\
\hline & $\begin{array}{l}\text { Lung contusion with } \\
\text { hemopneumothorax }\end{array}$ & 3 & 8.8 \\
\hline & None/Not reported & 18 & 52.9 \\
\hline \multirow[t]{5}{*}{ Associated vascular injury } & Innominate artery & 5 & 14.7 \\
\hline & $\begin{array}{l}\text { Left subclavian with Innominate } \\
\text { artery }\end{array}$ & 2 & 5.9 \\
\hline & Left common carotid artery & 1 & 2.9 \\
\hline & Right aberrant subclavian artery & 1 & 2.9 \\
\hline & None/Not reported & 25 & 73.5 \\
\hline \multirow[t]{5}{*}{ Other area injuries } & Face injury & 5 & 14.7 \\
\hline & Extremity injury & 17 & 50 \\
\hline & Abdominal injury & 13 & 38.2 \\
\hline & Traumatic brain injury & 13 & 38.2 \\
\hline & Vertebral injury & 5 & 14.7 \\
\hline
\end{tabular}

Table 6. Demographics, mechanism of injury and clinical manifestations of patients with Innominate artery injuries.

\begin{tabular}{llcc}
\hline Category & Subcategory & Number & Percentage(\%) \\
\hline Age category & $18-44$ years & 20 & 69.0 \\
\hline
\end{tabular}




\begin{tabular}{|c|c|c|c|}
\hline & 45 years and above & 9 & 31.0 \\
\hline \multirow[t]{2}{*}{ Sex } & Male & 26 & 89.7 \\
\hline & Female & 3 & 10.3 \\
\hline \multirow[t]{4}{*}{ Mechanism of injury } & Motor vehicle collision & 19 & 65.5 \\
\hline & Motor cycle injury & 4 & 13.8 \\
\hline & Fall from height & 5 & 17.2 \\
\hline & Sports injury & 1 & 3.4 \\
\hline \multirow[t]{9}{*}{ Clinical manifestations } & Chest pain & 7 & 24.1 \\
\hline & Blood pressure or pulse deficit & 6 & 20.7 \\
\hline & Altered mentation & 2 & 6.9 \\
\hline & Hemodynamic instability & 3 & 10.3 \\
\hline & Progressive supra-clavicular swelling & 1 & 3.5 \\
\hline & Ischemic limb pain & 1 & 3.5 \\
\hline & Decreased air entry & 1 & 3.5 \\
\hline & Other & 1 & 3.5 \\
\hline & Non-specified & 7 & 24.1 \\
\hline Related complaint & Polytrauma & 8 & 27.6 \\
\hline \multirow[t]{7}{*}{ Chest wall injury } & Rib fracture alone & 9 & 31.0 \\
\hline & Sternum fracture alone & 1 & 3.4 \\
\hline & Clavicle fracture & 1 & 3.4 \\
\hline & Sternum and rib fracture & 4 & 13.8 \\
\hline & Rib and clavicle fracture & 1 & 3.4 \\
\hline & Rib, clavicle and sternum fracture & 1 & 3.4 \\
\hline & None/not reported & 12 & 41.4 \\
\hline \multirow{6}{*}{$\begin{array}{l}\text { Lung parenchymal/ } \\
\text { intrathoracic injury }\end{array}$} & Pneumothorax alone & 3 & 10.3 \\
\hline & Hemothorax alone & 1 & 3.5 \\
\hline & Hemopneumothorax & 2 & 6.9 \\
\hline & Lung contusion alone & 3 & 10.3 \\
\hline & Lung contusion with hemopneumothorax & 3 & 10.3 \\
\hline & None/Not reported & 17 & 58.6 \\
\hline \multirow[t]{5}{*}{ Associated vascular injury } & Aorta & 1 & 3.5 \\
\hline & $\begin{array}{l}\text { Right subclavian and right common } \\
\text { carotid artery }\end{array}$ & 1 & 3.5 \\
\hline & Right aberrant subclavian artery & 1 & 3.5 \\
\hline & Superior vena cava injury & 1 & 3.5 \\
\hline & None/Not reported & 25 & 86.2 \\
\hline \multirow[t]{5}{*}{ Other area injuries } & Face injury & 8 & 27.6 \\
\hline & Extremity injury & 8 & 27.6 \\
\hline & Abdominal injury & 3 & 10.3 \\
\hline & Traumatic brain injury & 4 & 13.8 \\
\hline & Vertebral injury & 3 & 10.3 \\
\hline \multirow[t]{3}{*}{ Seatbelt sign } & Yes & 6 & 20.7 \\
\hline & No & 3 & 6.9 \\
\hline & Not reported & 21 & 72.4 \\
\hline
\end{tabular}


nearly half of the patients had 1 or more pulmonary of injury in more than $80 \%$ of the patients in this reinjuries. This high occurrence is still lower than that view, which is similar to the $88.9 \%$ reported by Hirose of the autopsy reports of patients with thoracic aorta and Gill. Chest pain and blood pressure/pulse discrepinjuries ${ }^{[112]}$.

Innominate artery injuries were most commonly assoancies were the 2 dominant manifestations, occurring ciated with aortic injuries, and although prior studies linking aortic and innominate artery injury are not available, this association is logical. Similar trauma mechanisms and anatomic proximity make both vessels vulnerable simultaneously.

CT scanning was the diagnostic modality of choice in nearly half of the patient cases in the present review ${ }^{[113]}$. This is consistent with the recommendation from Mirvis et al., who argue that, given its sensitivity and specificity of greater than $90 \%$, the CT scan is a good option for traumatic aortic injury diagnosis. In fact, an additional $1 / 5$ th of patientsin the present review underwent CT angiography, further decreasing the need for conventional/digital subtracted angiography.

In the present review, most patients (52.9\%) had injuries either at the isthmus or the descending aorta.This is slightly lower than in other studies. For instance, Williams et al. reported that $65 \%$ of the reviewed injuries occurred at the isthmus or the descending aorta ${ }^{[114]}$. Pseudoaneurysm was the most common vascular lesion in this review. This is similar to other findings in the literature, including those of Starnes et al., in which pseudoaneurysm was reported among 71\% of the blunt aortic injury patients ${ }^{[115]}$.

Endovascular repair was the most common modality of thoracic aorta repair in the present review. In fact, with the introduction of the hybrid method, close to $2 / 3$ rds of patients underwent a minimally invasive corrective procedure with either total endovascular or hybrid techniques. This data is similar to the findings of Gombert et al.,in which $62.8 \%$ of patients underwent an endovascular procedure. However, contrary to what Gombert et al. reported, this review did not find patients who underwent conservative management with no surgical intervention ${ }^{[111]}$. Graft repair was the most common method of open repair in the present review.

The present review revealed a $6 \%$ mortality rate, which is significantly lower than the rates reported by large reviews, such as that by Gombert et al.,in which a $40.8 \%$ rate of total mortality was reported ${ }^{[111]}$. This level of staggering difference may be attributed to the fact that the case reports and case series in the present review are those of living patients rather than fatalities.

\section{Innominate artery injury}

The mean ages of the thoracic aorta and innominate artery injury patients are quite similar. The high male predominance $(89.7 \%)$ identified in this review is consistent with the results of an older review by Hirose and Gill, which showed a male predominance of $86.3 \%$. Motor vehicle related-accidents were the mechanism in almost half of the patients in the present review. Hirose and Gill reported that 20 out of 132 patients (15.15\%) experienced blood pressure/pulse deficits even though thy didn't report on Chest pain ${ }^{[90]}$.

On the subject of associated injuries, this review found rib fractures in almost half of the reported cases, polytrauma in $1 / 4$ th of the reports, and a significant number $(41.4 \%)$ of instances of at least 1 pulmonary injury. Hirose and Gill reported a significantly lower rate of rib fractures (16 out of 132 cases, 12.1\%). Similarly, Hirose and Gill reported only 28 out of 132 patients experiencing pulmonary complications, which is also significantly lower than the rate obtained in this review. The reason for these discrepancies is unknown. The rate of head injury, at $13.8 \%$ in this review, is comparable to that in the report from Hirose and Gill, in which 15 out of 132 patients $(11.4 \%)$ experienced a traumatic brain injury ${ }^{[90]}$. The seatbelt sign status was reported in 8 patients in the present review, of which 6 had a seatbelt sign, which can indicate a sudden deceleration injury that may have caused the innominate artery injuries.

Although $62 \%$ of patients in this review underwent a diagnostic angiography, this invasive modality seems to be decreasing in popularity. Hirose and Gill reported that in all of their reviewed cases with a reported imaging modality, diagnostic conventional angiography was used, which caused the authors to conclude that angiography is the gold standard modality. This shows a slow yet steady increase in the utilization of noninvasive diagnostic modalities such as CT with contrast and CT angiography.

The present review found pseudoaneurysm in more than half of the cases. This correlates well with similar review findings on thoracic aorta and subclavian artery injuries ${ }^{[90]}$.

In the innominate artery injury cases examined in the present review, open repair was the most common management modality (in contrast with the for aortic and subclavian artery repair, for which endovascular intervention was preferred more often). Hirose and Gill did not report any endovascular procedures in the case reports reviewed prior to 2003. Although the progress towards endovascular and hybrid techniques may be slower compared to aortic and subclavian artery injury repairs, more and more surgeons have been utilizing endovascular interventions in recent years ${ }^{[90]}$.

In the present review, complications with cerebrovascular accidents occurred in $10 \%$ of the patient cases, and all of these complications occurred in the open surgical repair group and none in innominate artery injury patients treated with endovascular interventions. This could be due to selection bias because more stable patients may have been more likely to be managed with endovascular techniques than those undergoing 
open repairs.

\section{CONCLUSION}

In subclavian artery injuries, clavicular fracture can point to arterial injuries, especially in older patients. Blood pressure/pulse deficits were the most common clinical indicators of these injuries.Investigations using CT with contrast, CT angiography, or conventional angiography are typically performed in these cases, with no clear preference of any one over the others. Open repair is still the most common treatment modality, with an increasing use of endovascular techniques.

Blunt thoracic aortic injuries are common among highspeed deceleration injuries. Chest pain in a patient with a significant trauma mechanism is a good indicator that further investigation is needed, especially when associated with head trauma or polytrauma. A CT scan can be the first and even the modality of choice for this investigation. Endovascular procedures can be considered regardless of the type of vascular lesion. Innominate artery injury is a predominantly motor vehicle-related injury. Chest pain and blood pressure/ pulse deficits are the most common clinical features of this injury. Suspected innominate artery injuries may need conventional/digital subtracted angiography, and the threshold for performing these tests should be lower. Open surgical management is still the procedure of choice, and until further knowledge is gained, there can be no recommendation to replace this time-tested technique.

\section{DECLARATIONS}

\section{Conflicts of interest}

All authors declare that there are no conflicts of interest.

\section{REFERENCES}

1. Heron, M. P. (2019). National Vital Statistics report: Deaths: leading causes for 2017 June 24 2019, 68(6) 1-77.

2. Moodley, N. B., Aldous, C., \& Clarke, D. L. (2014). An audit of trauma-related mortality in a provincial capital in South Africa. South African Journal of Surgery, 52(4), 101-104.

3. Byun, C. S., Park, I. H., Oh, J. H., Bae, K. S., Lee, K. H., \& Lee, E. (2015). Epidemiology of trauma patients and analysis of 268 mortality cases: trends of a single center in Korea. Yonsei medical journal, 56(1), 220-226.

4. World Health Organization. (2015). Global status report on road safety 2015 . World Health Organization.

5. World Health Organization. Violence, Injury Prevention, \& World Health Organization. (2013). Global status report on road safety 2013: supporting a decade of action. World Health Organization.

6. Baghi, I., Herfatkar, M. R., Shokrgozar, L., Poor-Rasuli, Z., \& Aghajani, F. (2015). Assessment of vascular injuries and reconstruction. Trauma monthly, 20(4).

7. Perkins, Z. B., De'Ath, H. D., Aylwin, C., Brohi, K., Walsh, M., \& Tai, N. R.M. (2012). Epidemiology and outcome of vascular trauma at a British Major Trauma Centre. European journal of vascular and endovascular surgery, 44(2), 203-209.

8. Mattox, K. L., Feliciano, D. V., Burch, J., Beall Jr, A. C., Jordan Jr, G. L., \& De Bakey, M. E. (1989). Five thousand seven hundred sixty cardiovascular injuries in 4459 patients. Epidemiologic evolution 1958 to 1987. Annals of surgery, 209(6), 698.

9. Baker, C. C., Oppenheimer, L., Stephens, B., Lewis, F. R., \& Trunkey, D. D. (1980). Epidemiology of trauma deaths. The American Journal of Surgery, 140(1), 144-150.

10. Sobrino, J., \& Shafi, S. (2013, April). Timing and causes of death after injuries. In Baylor University Medical Center Proceedings (Vol. 26, No. 2, pp. 120-123). Taylor \& Francis.

11. O'Connor JV, Byrne C, Scalea TM, Griffith BP, Neschis DG. (2019). Vascular injuries after blunt chest trauma: diagnosis and management. Scand J Trauma Resusc Emerg Med, 17, 1-10.

12. Fatimi, S. H., Anees, A., Muzaffar, M., \& Hanif, H. M. (2010). Acute traumatic subclavian artery thrombosis and its successful repair via resection and end-to-end anastomosis. Chinese Journal of Traumatology (English Edition), 13(4), 255-256.

13. Stefańczyk, L., Czeczotka, J., Elgalal, M., Sapieha, M., \& Rowiński, O. (2011). A large posttraumatic subclavian artery aneurysm complicated by artery occlusion and arteriobronchial fistula successfully treated using a covered stent. Cardiovascular and interventional radiology, 34(2), 146-149.

14. Günday, M., Özülkü, M., Yıldırım, E., Güven, A., \& Çiftçi, Ö. (2013). Successful endovascular treatment of subclavian artery dissection after compression trauma. The American journal of emergency medicine, 31(2), 457-e1.

15. Sandiford, N., Tsitskaris, K., \& Erritty, M. (2010). Delayed presentation of a pseudoaneurysm of the subclavian and axillary artery-the importance of vigilance. Journal of the Royal Society of Medicine, 103(2), 67-69.

16. Fudurić, J., Erdeljac, Ž., Frketić, I., Miletić, M., Šoštarić Zadro, A., Bačić, I., ... \& Missoni, E. (2014). Blunt Trauma of Thorax with Subclavian and Axillary Artery Lesion-Case Report. Collegium antropologicum, 38(3), 1055-1057.

17. Assenza, M., Centonze, L., Valesini, L., Campana, G., Corona, M., \& Modini, C. (2012). Traumatic subclavian arterial rupture: a case report and review of literature. World Journal of Emergency Surgery, 7(1), 18.

18. Queiroz, R. M., Santana, D. B. F. D., Roque, D., Bernardes Filho, F., Febronio, E. M., \& Valentin, M. V. N. (2018). Blunt thoracic trauma with the formation of pseudoaneurysm with the junction of the right subclavian artery. Revista da Associação Médica Brasileira, 64(11), 987-989.

19. Serrano, J. A., Rodriguez, P., Castro, L., Serrano, P., \& Carpintero, P. (2003). Acute subclavian artery pseudoaneurysm after closed fracture of the clavicle. Acta orthopaedica belgica, 69(6), 555-557.

20. Derom, A., Ottenheim, S., Raat, H., \& van Kleef, J. (2008). Endovascular treatment of acute subclavian pseudo-an- 
eurysm after fracture of the clavicle. Acta Chirurgica Belgica, 108(4), 441-443.

21. Baikoussis, N. G., Siminelakis, S. N., Matsagas, M., \& Michalis, L. K. (2010). Massive haemothorax due to subclavian artery rupture: Emergency thoracotomy or primary stent-grafting?. Heart, Lung and Circulation, 19(7), 431.

22. Weber, C. D., Kobbe, P., Herren, C., Mahnken, A. H., Hildebrand, F., \& Pape, H. C. (2017). Endovascular management of a combined subclavian and vertebral artery injury in an unstable polytrauma patient: case reportand literature review. Bulletin of emergency and trauma, 5(1), 53-57.

23. Campfield, B., \& Barzideh, O. S. (2016). Clavicular Fracture Associated with Life-Threatening Hemorrhage: A Case Report. JBJS case connector, 6(2), e31.

24. Yonezawa, N., Nakayama, Y., Takei, T., Toh, M., Asano, M., Imamura, T., \& Ito, T. (2017). Fatal delayed rupture of the subclavian artery in a patient with first-rib fracture caused by blunt trauma. Clinical case reports, 5(3), 260.

25. Cheema, M., Kirton, O. C., Lukose, B., \& Gallagher, J. (2008). Ligation of the subclavian artery after blunt trauma presenting as massive hemothorax. Journal of Trauma and Acute Care Surgery, 64(4), 1126-1130.

26. Diaz-Gutierrez, I., Rana, M. A., Ali, B., Marek, J. M., \& Langsfeld, M. (2017). Hybrid Repair of Complex Left Subclavian Artery Injury with Partial Transection and Complete Thrombosis in an Unstable Patient following Blunt Trauma. Annals of vascular surgery, 40, 298-e11.

27. Elkbuli, A., Shaikh, S., McKenney, M., \& Boneva, D. (2019). Subclavian artery avulsion following blunt trauma: A case report and literature review. International journal of surgery case reports, $61,157-160$.

28. Enamorado-Enamorado, J., Egea-Guerrero, J. J., Revuelto-Rey, J., Gordillo-Escobar, E., \& Herrera-Melero, C. (2011). Left subclavian artery pseudoaneurysm after a traffic accident: a case report. Case reports in critical care, 2011.

29. Nakada, T. A., Idoguchi, K., Fukuma, H., Ono, H., Nakao, S., \& Matsuoka, T. (2014). Case report: urgent endovascular treatment of subclavian artery injury after blunt trauma. F1000Research, 3.

30. Gullo, J., Singletary, E. M., \& Larese, S. (2013). Emergency bedside sonographic diagnosis of subclavian artery pseudoaneurysm with brachial plexopathy after clavicle fracture. Annals of emergency medicine, 61(2), 204-206.

31. Hirose, H., \& Temes, R. T. (2005, December). Acute subclavian artery occlusion by blunt trauma: a case report. In HEART SURGERY FORUM (Vol. 8, No. 6, p. 360)

32. Ipaktchi, R., Dettmer, S., Vogt, P. M., \& Knobloch, K. (2010). Subclavian artery and jugular vein rupture after a blunt thoracic trauma due to a BMX handlebar. European journal of cardio-thoracic surgery, 12(1), 235.

33. Jaiswal, L. S., Prasad, J. N., Maharjan, R., \& Pandit, N. (2018). Giant pseudoaneurysm of subclavian artery after blunt chest trauma. Journal of vascular surgery cases and innovative techniques, 4(3), 220-222.

34. Ostovan, M. A., Kojuri, J., \& Dehghani, P. (2017). Endovascular Repair of the Traumatic Dissection of the Subclavian-Axillary Artery: Report of Four Cases. The Journal of
Tehran University Heart Center, 12(2), 88.

35. Kapetanakis, E. I., Sears-Rogan, P., Young, R. S., Kanda, L. T., \& Ellis, J. L. (2006). Traumatic partial avulsion of a single right subclavian artery from the aortic arch and definitive repair. The Annals of thoracic surgery, 81(1), 348-350.

36. Karkos, C. D., Mair, R., Markose, G., Fishwick, G., London, N. J., \& Naylor, A. R. (2007). Hybrid procedures combining open and endovascular surgical techniques for the management of subclavian artery injuries. Journal of Trauma and Acute Care Surgery, 63(5), E107-E110.

37. Noh, D., Lee, C. K., Hwang, J. J., \& Cho, H. M. (2018). Concomitant avulsion injury of the subclavian vessels and the main bronchus caused by blunt trauma. The Korean journal of thoracic and cardiovascular surgery, 51(2), 153.

38. Kluemper, C., Koestner, T., Cowart, J., \& Higgins, M. (2018). Intercostal Entrapment of Clavicle Fracture Causing a Pulseless, Flaccid Upper Extremity. The Journal of hand surgery, 43(12), 1143-e1.

39. Knobloch, K., von Falck, C., Teebken, O., \& Krettek, C. (2006). Scapulothoracic dissociation with subclavian artery dissection following a severe motorbike accident. European journal of cardio-thoracic surgery, 30(4), 671-671.

40. Sabbagh, C. N., Chowdhury, M. M., Durrani, A., Van Rensburg, L., Koo, B., \& Coughlin, P. A. (2016). A Novel Combined Hybrid Approach to Enable Revascularisation of a Trauma-Induced Subclavian Artery Injury. EJVES short reports, 32, 18-20.

41. Mirza, W. R., \& Shiraev, T. P. (2018). Endovascular Management of a Left Subclavian Artery Pseudoaneurysm Secondary to Clavicular Fracture. European Journal of Vascular and Endovascular Surgery, 55(5), 624.

42. Wan Ismail Faisham, P. M., Juhara, H., Munirah, N. M., Shamsulkamaruljan, H., \& Ziyadi, G. M. (2011). Clavicle fracture and subclavian vessels disruption with massive haemothorax mimic intrathoracic injury. The Malaysian journal of medical sciences: MJMS, 18(2), 74.

43. Quinones-Baldrich, W. J. (2010). Right subclavian pseudoaneurysm secondary to blunt trauma in an arteriovenous malformation. Journal of vascular surgery, 51(1), 228-229.

44. Gill, I., Quayle, J., \& Fox, M. (2013). A low energy paediatric clavicle fracture associated with acute brachial plexus injury and subclavian artery compression. The Annals of The Royal College of Surgeons of England, 95(2), e6-e9.

45. Rodriguez-Merchan, E. C., \& Gomez-Cardero, P. (2010). Delayed union of a fracture of the middle third of the clavicle presenting with a late subclavian pseudoaneurysm. Musculoskeletal surgery, 94(2), 89-92.

46. Scheffler, P., Uder, M., Gross, J., \& Pindur, G. (2003). Dissection of the proximal subclavian artery with consecutive thrombosis and embolic occlusion of the hand arteries after playing golf. The American journal of sports medicine, 31(1), 137-140.

47. Sodhi, K. S., Arora, J., \& Khandelwal, N. (2007). Post-traumatic occlusion of subclavian artery with clavicle fracture. Journal of Emergency Medicine, 33(4), 419-420.

48. Zaharudin, I., Azizi, Z. A., \& Govindarajanthran, N. (2016). Traumatic right proximal subclavian artery pseudoaneu- 
rysm treated with a hybrid procedure: a case report. Med J Malaysia, 71(4), 221.

49. Tachtsi, M. D., Pitoulias, G. A., Fycatas, P., Kalogirou, T., \& Papadimitriou, D. K. (2011). Subclavian artery aneurysm due to clavicle fracture. Annals of vascular surgery, 25(7), 984-e5.

50. Tennyson, C., Karunaratne, D., McLaughlin, K. E., Hasan, R., \& Grant, S. W. (2018). Delayed subclavian artery rupture secondary to a traumatic first rib fracture. Trauma case reports, $16,1$.

51. Mandal, A. K. J., Jordaan, J., \& Missouris, C. G. (2004). Fractured clavicle and vascular complications. Emergency medicine journal, 21(5), 648-648.

52. Van Schaik, P. M., de Borst, G. J., Moll, F. L., \& Toorop, R. J. (2015). Late onset acute occlusion of the subclavian artery after clavicle fracture. Vascular, 23(6), 661-662.

53. Watanabe, K., \& Matsumura, T. (2005). Late-onset brachial plexus paresis caused by subclavian pseudoaneurysm formation after clavicular fracture. Journal of Trauma and Acute Care Surgery, 58(5), 1073-1074.

54. Zhang, M., Yuan, Y., Hu, Y., Zhao, Y., Liu, H., \& Lu, H. (2015). Urgent endovascular treatment of proximal right subclavian artery pseudoaneurysm using kissing technique. Annals of vascular surgery, 29(6), 1319-e1.

55. Butterworth, S. A., Ng, A. K., Janusz, M. T., \& Simons, R. K. (2001). Great vessel injury after hockey-related trauma: two case reports and a literature review. Journal of Trauma and Acute Care Surgery, 51(4), 796-799.

56. Sladojevic, M., Markovic, M., Ilic, N., Pejkic, S., Banzic, I., Djoric, P., ... \& Davidovic, L. (2016). Open Treatment of Blunt Injuries of Supra-Aortic Branches: Case Series. Annals of vascular surgery, 31, 205-e5.

57. Bukhari, H. A., Saadia, R., \& Hardy, B. W. (2007). Urgent endovascular stenting of subclavian artery pseudoaneurysm caused by seatbelt injury. Canadian journal of surgery, 50(4), 303.

58. Matsumoto, M., Tanemoto, K., Inagaki, E., Hamanaka, S., Masaki, H., Nakata, M., ... \& Tabuchi, A. (2006). Traumatic rupture of a right aortic arch in a patient with an aberrant left subclavian artery. The Journal of thoracic and cardiovascular surgery, 131(2), 464-465.

59. Benedetto, F., La Spada, M., Stilo, F., De Caridi, G., Cotroneo, A., Passari, G., \& Spinelli, F. (2008). Endovascular repair in atypical traumatic rupture of thoracic aorta. Il Giornale di chirurgia, 29(10), 427-428.

60. Badmanaban, B., Diver, A., Ali, N., Graham, A. N., McGuigan, J., \& MacGowan, S. (2003). Traumaticaortic rupture during pregnancy. Journal of cardiac surgery, 18(6), 557-561.

61. Boulate, D., Fabre, D., Langer, N. B., \& Fadel, E. (2018). Ascending aorta, aortic arch and supra-aortic vessels rupture in blunt thoracic trauma. Interactive cardiovascular and thoracic surgery, 27(2), 304-306.

62. Chock, M. M., Aho, J., Naik, N., Clarke, M., Heller, S., \& Oderich, G. S. (2015). Endovascular treatment of distal thoracic aortic transection associated with severe thoracolumbar spinal fracture. Vascular, 23(5), 550-552.

63. Coppi, G., Tshomba, Y., Psacharopulo, D., Marone, E. M., \& Chiesa, R. (2012). Aberrant right subclavian artery in blunt aortic injury: implication for treatment and review of the literature. Annals of vascular surgery, 26(6), 861-e1.

64. Eckhauser, A. W., Hannon, D., Molitor, M., Scaife, E., \& Gruber, P. J. (2013). Repair of traumatic aortoinnominate disruption using CorMatrix. The Annals of thoracic surgery, 95(4), e99-e101.

65. Waldenberger, P., Fraedrich, G., Mallouhi, A., Jaschke, W. R., Perkmann, R., Jung, T., \& Czermak, B. V. (2003). Emergency endovascular treatment of traumatic aortic arch rupture with multiple arch vessel involvement. Journal of Endovascular Therapy, 10(4), 728-732.

66. Gilani, R., Ochoa, L., Wall Jr, M. J., Tsai, P. I., \& Mattox, K. L. (2011). Endovascular repair of traumatic aortic injury using a custom fenestrated endograft to preserve the left subclavian artery. Vascular and endovascular surgery, 45(6), 549-552.

67. Gombert,A., Barbati, M.E., Grommes,J.,Jalaie,H.,Schleimer, K., Jacobs, M. J., \& Kalder, J. (2016). Blunt thoracic aortic injury in case of a 15-year-old boy: difficulties and possibilities of the endovascular approach. Annals of vascular surgery, 33, 228-e15.

68. Ryu, Y. G., Choo, S. J., Lim, J. Y., Yoon, H. K., \& Chung, C. H. (2010). Hybrid procedure for a traumatic aortic rupture consisting of endovascular repair and minimally invasive arch vessel transposition without sternotomy. Journal of Korean medical science, 25(1), 142.

69. Ktenidis, K., Lioupis, A., Giannopoulos, A., Ginis, G., \& Kiskinis, D. (2012). Management of traumatic aortic isthmus rupture in case of aberrant right subclavian artery (arteria lusoria). Annals of vascular surgery, 26(3), 421-e1.

70. Kovari, V. Z., Pecsi, F., Janvari, M. C., \& Veres, R. (2017). Initial experience with the treatment of concomitant aortic pseudoaneurysm and thoracolumbar spinal fracture: Case report. Trauma case reports, 12, 48-53.

71. Mattison, R., Hamilton Jr, I. N., Ciraulo, D. L., \& Richart, C. M. (2001). Stent-graft repair of acute traumatic thoracic aortic transection with intentional occlusion of the left subclavian artery: case report. Journal of Trauma and Acute Care Surgery, 51(2), 326-328.

72. Moore, R. D., \& Brandschwei, F. (2001). Subclavian-to-carotid transposition and supracarotid endovascular stent graft placement for traumatic aortic disruption. Annals of vascular surgery, 15(5), 563-566.

73. Murphy, E. H., Dimaio, J. M., Dean, W., Jessen, M. E., \& Arko, F. R. (2009). Endovascular repair of acute traumatic thoracic aortic transection with laser-assisted in-situ fenestration of a stent-graft covering the left subclavian artery. Journal of Endovascular Therapy, 16(4), 457-463.

74. Piffaretti, G., Carrafiello, G., Ierardi, A. M., Mariscalco, G., Macchi, E., Castelli, P., ... \& Franchin, M. (2015). Thoracic endovascular aortic repair for blunt thoracic aortic injuries in complex aortic arch vessels anatomies. Annals of vascular surgery, 29(6), 1320-e11.

75. Patel, K., Allen, K., Hinrichs, C., Jihayel, A., \& Donahoo, J. S. (2002). Traumatic aortic arch injury. The Annals of thoracic surgery, 73(2), 666.

76. Gandhi, S. K., Von Haag, D., Webber, S. A., \& Pigula, F. A. (2003). Traumatic aortic transection in a child with an 
anomalous right subclavian artery. The Annals of thoracic surgery, 76(6), 2087-2089.

77. Leshnower, B. G., Litt, H. I., \& Gleason, T. G. (2006). Anterior approach to traumatic mid aortic arch transection. The Annals of thoracic surgery, 81(1), 343-345.

78. Serna, D. L., Miller, J. S., \& Chen, E. P. (2006). Aortic reconstruction after complex injury of the mid-transverse arch. The Annals of thoracic surgery, 81(3), 1112-1114.

79. Propper, B. W., Alley, J. B., Gifford, S. M., Burkhardt, G. E., \& Rasmussen, T. E. (2009). Endovascular treatment of a blunt aortic injury in Iraq: extension of innovative endovascular capabilities to the modern battlefield. Annals of vascular surgery, 23(5), 687-e19.

80. Reynolds, T. S., Donayre, C. E., Somma, C. G., Poggio, W. G., Kim, K. M., Nguyen, T., \& White, R. (2011). Endovascular management of blunt aortic injury with an associated aberrant right subclavian artery: a report of three cases. Annals of vascular surgery, 25(7), 979-e7.

81. Siddiqi, M. S., Sharma, A. K., \& Sabti, H. A. (2015). Polytrauma to right diaphragm, descending thoracic aorta, and innominate artery. Asian cardiovascular and thoracic annals, 23(9), 1075-1078.

82. Thompson, J. K., Reed, A. B., \& Giglia, J. S. (2006). Novel endovascular treatment of blunt thoracic aortic trauma with a self-expanding stent lined with aortic extender cuffs. Annals of vascular surgery, 20(2), 271.

83. Turhan, H., Topaloglu, S., Cagli, K., Sasmaz, H., \& Kutuk, E. (2004). Traumatic type B aortic dissection causing near total occlusion of aortic lumen and diagnosed by transthoracic echocardiography: A case report. Journal of the American Society of Echocardiography, 17(1), 80-82.

84. Waldenberger, P., Fraedrich, G., Mallouhi, A., Jaschke, W. R., Perkmann, R., Jung, T., \& Czermak, B. V. (2003). Emergency endovascular treatment of traumatic aortic arch rupture with multiple arch vessel involvement. Journal of Endovascular Therapy, 10(4), 728-732.

85. Yeo, D. L. T., Haider, S., \& Zhen, C. A. C. (2015). Blunt traumatic aortic injury of right aortic arch in a patient with an aberrant left subclavian artery. The Yale journal of biology and medicine, 88(1), 93.

86. Al-khaldi, A., \& Robbins, R. C. (2006). Successful repair of blunt injury of aortic arch branches in the setting of bovine arch. Journal of vascular surgery, 43(2), 396-398.

87. Dhaliwal, R. S., Luthra, S., Goyal, S., Behra, S., Krishna, R., \& $\mathrm{Ba}, \mathrm{K}$. (2005). Traumatic giant pseudoaneurysm of innominate artery. Asian Cardiovascular and Thoracic Annals, 13(4), 369-371.

88. Knosalla, C., Pasic, M., \& Hetzer, R. (2000). Traumatic dissection of the innominate artery. European Journal of Cardio-Thoracic Surgery, 18(3), 370-370.

89. Hirose, H., \& Gill, I. S. (2004). Blunt injury of proximal innominate artery. Annals of thoracic and cardiovascular surgery, 10(2), 130-132.

90. Hirose, H., \& Gill, I. S. (2004). Blunt injury of the innominate artery: a case report and review of literature. Annals of thoracic and cardiovascular surgery, 10(4), 218-223.

91. Stover, S., Holtzman, R. B., Lottenberg, L., \& Bass, T. L. (2001). Blunt innominate artery injury. The American surgeon, 67(8), 757.

92. Axisa, B. M., Loftus, I. M., Fishwick, G., Spyt, T., \& Bell, P. R. (2000). Endovascular repair of an innominate artery false aneurysm following blunt trauma. Journal of Endovascular Therapy, 7(3), 245-250.

93. Ben, S. O., Ben, M. H., Ben, M. M., Kaouel, K., Daoued, Z., \& Khayati, A. (2014). Traumatic dissection of the innominate artery. A case report. Journal des maladies vasculaires, 39(1), 73-76.

94. Bito, Y., Hirai, H., Sasaki, Y., Hosono, M., Nakahira, A., Suehiro, Y., ... \& Suehiro, S. (2014). Successful surgical treatment of traumatic transection of the innominate artery: a case report. Annals of vascular diseases, 7(2), 165-168.

95. Boutayeb, A., Porcu, P., Pirvu, A., \& Chavanon, O. (2014). Post-traumatic injury of the brachiocephalic artery: onpump beating heart repair. Heart, Lung and Circulation, 23(10), e226-e228.

96. Davidović, L., Ilić, N., Cvetković, S., Koncar, I., Čolić, M., \& Vjestica, M. (2011). Blunt injury of the innominate artery and left innominate vein. Vascular, 19(4), 223-225.

97. Dias-Neto, M., Ramos, J. F., \& Teixeira, J. F. (2018). Blunt Injury of the Innominate Artery: What Surprises to Expect? A Case Report. Vascular and endovascular surgery, 52(3), 226-232.

98. Miles EJ, Blake A, Thompson W, Jones WG, Dunn EL. (2003). Endovascular repair of acute innominate artery injury due to blunt trauma. Am Surg, 68(2), 155-159

99. Howea KL, Guirgisa G, Woodmana G, Chub GF, Cooperc MJ,Rapanosa T, Szalay D. (2017). Blunt innominate artery trauma requiring repair and carotid ligation. Trauma Case Reports, 12, 24-27

100.Huang C, Kao H. (2008). Endovascular Management of Post-Traumatic Innominate Artery Transection With Pseudo-Aneurysm Formation. Catheterization and Cardiovascular Interventions, 72, 569-572

101. Lee CW, Song S, Choi SU, Kim SH, Lee HC. (2015). Hybrid Repair for Anastomotic Pseudoaneurysm on the Innominate Artery Following Blunt Chest Trauma. J Card Surg, 30, 836-838

102. Mousa AY, Batsides GP, RV Todd. (2010). Delayed presentation of traumatic innominate artery injury. J Vasc Surg, 51,1014

103. Ormazabal A, Muangman N, Eric J. (2012). SternManubrial Fracture with an Associated Innominate Artery Injury: Curr Probl Diagn Radiol, 41(4), 122-123

104. Chu MWA, Myers ML. (2006). Traumatic Innominate Artery Disruption and Aortic Valve Rupture. Ann Thorac Surg, 82:1095-7

105. Roberts CS, Sadoff JD, White DR. (2000). Innominate Arterial Rupture Distal to Anomalous Origin of Left Carotid Artery. Ann Thorac Surg, 69, 1263-4

106. Symbas JD, Halkos ME, Symbas PN. (2005). Rupture of the Innominate Artery from Blunt Trauma: Current Options for Management. J Card Surg, 20, 455-459

107. Sturm JT, Dorsey JS, Oslon FR, Perry JF. (1984). The management of Subclavian artery injuries following blunt thoracic trauma. The annals of thoracic surgery, 38(3), 188-191 
108. Katras T, Baltazar U, Rush DS, Davis D, Bell TD, Browder IW, Compton RP, Stanton PE. (2001). Subclavian arterial injury associated with blunt trauma. Vascular surgery, 35, 43-50

109. Costa MC, Robbs JV. (1988). Non penetrating Subclavian artery trauma. Journal of vascular surgery, 8(1): 71-75

110. Road safety annual report 2018: International transport forum. https://www.itf-oecd.org/sites/default/diles/ docs/irtad-road-safety-annual-report-2018_2.pdf

111. Gombert A, Barbati ME, Storck M, Kotelis D, Keschenau P, Pape H, Andruszkow H, Lefering R, Hilderbrand F, Greiner A, Jacobs MJ, Grommes J. (2017). Treatment of blunt thoracic aortic injury in Germany-Assessment of the TraumaRegister DGU, 12(3), 1-12
112. Burkhart HM, Gomez GA, Jacobson LE, Pless JE, Broadie TA. (2001). Fatal blunt aorticinjuries: A review of 242 autopsy cases. J Trauma, 50, 113-115

113. Mirvis SE, Shanmuganathan K, Miller BH, White CS, Turney SZ. (1996). Traumatic aortic injury: Diagnosis with contrast-enhanced CT-Five year experience of a major trauma center. Radiology, 200(2), 413-422

114. Williams JS, Graff JA, Uku JM, Steining JP. (1995). Aortic injury in vehicular trauma. Ann Thorac Surg, 57, 726-730

115. Starnes BW, Lundgren RS, Gunn M, Quade S, Hatsukami TS, Tran NT, Mokadam N, Aldea G. (2012). A new classification scheme for treating blunt aortic injury. J vasc surg, 55(1), 47-54 